ESJ Humanities

\title{
Swearing on Twitter: Khaleeji Dialect
}

\author{
Abdullah Al-Qattan \\ Public Authority for Applied Education and Training, Kuwait
}

\section{Doi:10.19044/esj.2021.v17n33p151}

Submitted: 19 August 2021

Accepted: 13 September 2021

Published: 30 September 2021
Copyright 2021 Author(s)

Under Creative Commons BY-NC-ND

4.0 OPEN ACCESS

Cite As:

Al-Qattan A. (2021). Swearing on Twitter: Khaleeji Dialect. European Scientific Journal, ESJ, 17 (33), 151. https://doi.org/10.19044/esj.2021.v17n33p151

\begin{abstract}
Swearing is an inevitable part of any language and culture around the world, yet each culture has its own distinctive swear words and phrases used among its members. This language phenomenon is observed on Twitter, one of the most popular social network platforms where heated comments often occur. In this study, the examination of the Khaleeji dialect of the Arabian Gulf countries on Twitter reflects the influence of culture, religion, and language on the perception and use of swearing in the Arabian Gulf. Upon corpus-based categorization and analysis of one hundred swear words and phrases written by Khaleejis on Twitter, the data shows that Khaleejis refer to ten different thematic swearing categories, with animals being their top reference. The findings accordingly answer the following questions: What swear words do Khaleejis often use? What is the logic behind opting for the swear words recorded?
\end{abstract}

Keywords: Swearing, Khaleeji dialect, social media, Twitter, corpus

\section{Introduction}

Social media in all its forms has become an essential part of everyone's life in recent years. Active users of social media, as well as passive users, use different social network platforms for various reasons, such as reading news, posting personal posts, watching videos, commenting on events, etc. In the Middle East specifically, the Arab Social Media Report survey in 2015 showed that the primary motive for using social media in the Middle East was connecting with people in general, indicated by $55 \%$ of the overall result. This, in turn, means that users are more likely to interact with other users, whether 
through interactive chats, expressing opinions, or inquiring about specific issues. Accordingly, it is possible that the language used on these platforms may be considered obscene or offensive in some cases (Mubarak et al., 2017), which could trigger many users to express their disapproval or negative stances in various ways. This can be easily seen on social media platforms as people interact with each other (Pamungkas et al., 2020), including but not limited to interactions of people from the Arabian Gulf.

The Cooperation Council of the Arab States of the Gulf consists of six countries: Kuwait, Oman, Saudi Arabia, United Arab Emirates, Qatar, and Bahrain. However, due to Iraq's cultural and linguistic similarities with the rest of the countries of the council, many people consider Iraq part of the Gulf countries, which are also called "Khaleeji countries." Hence, in this study, the aforementioned seven countries are considered Khaleeji countries, where different forms of social media are used even though each country favors certain platforms over others. Many surveys on social media show that Facebook is the most used application in the Middle East overall. Yet, Radcliffe and Lam (2018) show that Facebook usership dropped from $76 \%$ to $55 \%$ in Saudi Arabia, in UAE from $83 \%$ to $70 \%$, and in Qatar from $43 \%$ to $22 \%$. However, it is difficult to validate whether the accounts are active since many users may have inactive accounts for their own reasons. Although not statistically proven, active usership of Facebook, for example, is almost nonexistent in Kuwait as Kuwaitis prefer other platforms such as Instagram, Snapchat, and mainly Twitter.

Since Twitter is rich with controversial topics where heated comments and discussions occur (Pamungkas et al., 2020), the phenomenon of swearing on Twitter is addressed in this study through corpus-based analysis to answer the following questions: What words or phrases do Khaleejis often use to swear? What is the logic behind opting for the swear words recorded? These questions initially target the Khaleeji dialect from a linguistic perspective, but their answers will provide rich information about the notion of swearing in the Khaleeji culture. In the analysis process, controversial tweets were examined on topics that would trigger Twitter users to swear freely without any external factors influencing their swearing decisions. Therefore, religious and political subjects were avoided since they are considered not only taboo but also so sensitive that many people choose to avoid them to prevent legal action from being taken against them. Instead, the data involved tweets on a specific international soccer-related topic since it is the most popular sport in the region, one which people take seriously and about which they express their opinions freely. Data collection methods will be explained in further detail in this paper. 


\section{Literature Review Swearing}

First, the notion of swearing has been approached in several studies under different names, including but not limited to swear words, profanity, and cursing. It has been explained and defined differently in several studies, all of which were approached from diverse perspectives. Some scholars opted for general definitions such as that of Finn (2017): "Swearing, a linguistic universal, is used to express intense emotions (fear, joy, anger, excitement)" (p. 18), while others opted for more detailed definitions such as that of Vingerhoets et al. (2013): "a form of linguistic activity utilizing taboo words to convey the expression of strong emotions" (p. 287). For the sake of this paper, swearing is defined as any word or phrase that associates a negative quality to the target referent in the Khaleeji culture. Mercury (1995) states that all obscene language is taboo language because the use of these expressions in public is restricted in some way. However, swearing is based on a culture's taboo categories (Vingerhoets et al., 2013), which indicates that what is considered obscene or offensive in one culture might not be the case in another. Accordingly, the continuum of politeness and rudeness around the world is vague since there is no unified, universal line that determines appropriate use of language across all languages or cultures; every culture has its own politeness-impoliteness continuum and words that are considered to be swearing (Jay \& Janschewitz, 2008). Swear words are generally defined by social codes. For instance, as covered later in this study, calling someone a cow in China has an entirely different implication than in the United States.

Swearing is often used connotatively based on certain emotional nuances associated with each swear word or phrase (Taylor, 1995). That is, although swear words may have clear denotative or literal meanings, they are usually not perceived based on that denotative or literal meaning. For instance, when someone shouts "Shit!" due to accidentally hitting the table with their elbow, people nearby would not expect to see feces around the table; this word is commonly perceived as an explicit expression of emotion. This recalls the discussion mentioned earlier: swear words and phrases do not have universal perception in all cultures worldwide. It is possible, therefore, that in some cultures, shouting "Shit!" would be understood denotatively or literally. Accordingly, swearing is culture-based since each culture has its own perspective, ideas, and understandings of different tangible objects and abstract concepts. In the end, swearing is a product of language itself, and language reflects the practices, perspectives, products, and members of the culture (Moran, 2001). Therefore, analyzing Khaleeji dialect or cultural swearing on Twitter enhances our knowledge of how people in the area practice culture through language. 


\section{Data Collection Method}

One hundred tweets on Twitter were collected that included swear words or phrases about a controversial soccer-related topic; they were compiled into a corpus. The tweets search process was completely random; different soccer news accounts were visited then tweets about the target topic in their timelines were investigated. In this stage, tweets written by other accounts replying to those tweets were examined; if a tweet has swear words, then the owner's nationality is checked. If he/she was proved to be a Khaleeji, the tweet was finally recorded in the corpus. One of the challenges was to detect Khaleeji accounts on Twitter since they do not necessarily include information about their owners' nationalities. Hence, besides looking for tweets written in Khaleeji dialects, different techniques were followed to confirm the owners' nationalities. This involved checking the profile picture of the accounts, the followers and followings, as well as any clues in their bio or in their profile in general that would reveal their nationalities. Now it is essential to know the context in which the phenomenon of swearing takes place for full comprehension of the target swearing used (Jay \& Janschewitz, 2008; Allan \& Burridge, 1991). The topic includes a soccer player, Mauro Icardi, being stripped of the captaincy armband of an Italian team due to problems with his agent, Wanda Nara, who is also his wife, as she had spoken unprofessionally or disrespectfully about the team. Accordingly, the recorded swear words were in regard to the player, his wife, the club, the club management, the fans, or any other related referents in this context. As mentioned earlier, the logic behind focusing on an international soccer-related topic is that other religious or political topics might confine writers and control their choice of words, as they fear legal consequences; religion and politics are sensitive topics in the Gulf area since the law does not tolerate offenders against religion or public political figures in the region.

After the data was collected, the swear words were classified thematically based on their semantic references (e.g., "زق" [shit] is classified as shit-related swearing). Then the data was analyzed based on the knowledge gained from all the references mentioned in this paper to clarify what these swear words reflect about swearing in Khaleeji dialect. In other words, the references in this paper were investigated to justify how and why the swear words recorded were used from cultural, religious, as well as linguistic perspectives. In the data collection process, linguistically manipulated swear words were also collected for the sake of this paper. For instance, in one of the tweets, "جحيييي" (heeeell) had three ي letters extending the word but was still included in the data. Also, some tweets had more than one swear word; the one that was more emphasized was chosen in this case. 


\section{Results and Discussion}

\section{Animals}

Animal-related words and phrases were the most common swearing category, accounting for $34 \%$ of the overall data collected. After close analysis of each sample, sheep were mentioned in exactly half of the samples, then dogs with $35 \%$, and finally donkeys, bulls, and a general reference to the word "animal," with $3 \%$ for each category.

Figure 1: Thematic distribution of swearing



Figure 2: Categorization of animal-related swearing




Animals, in general, have different connotations in cultures around the world. In their paper, Anjomshoa and Sadighi (2015) cover the different connotations between the English and Persian animal words. They state: "These differences are caused by religion, history, geographical environment, customs, and so on" (Anjomshoa \& Sadighi, 2015, p. 76). Therefore, all the recorded animal-related words in the data were examined from the aforementioned perspectives in order to thoroughly understand the logic behind referring to these animals in specific in swearing.

"Animal" in General

There was only one tweet from the database in which the word "animal" was mentioned in general without specifying a particular animal: "ايكاردي حيوان" (Icardi is an animal). The widespread use of animal metaphors is based on the hierarchical structure in which humans stand above animals. Hence, referring to animals-including the term "animal" itselfreinforces the speaker's superiority over the addressee, as it excludes the addressee from the superlative humanistic structure. Humans are considered civil and smart creatures, unlike animals; therefore, by calling someone "animal" in general, the speaker assigns him/her with negative attributes such as depravity and stupidity (Haslam, 2017).

"Sheep"

Many newspapers and online articles in the Gulf countries, including those by Alhaidari (2014) and Alodhaidan (2015), have discussed the implication of calling males - especially those who are married - sheep in an adjective or noun form (e.g., a sheep husband). In general, and based on the articles mentioned, married men are called or referred to as sheep when they show extreme obedience to their wives, as they either follow them blindly, accept all their requests unconditionally, or fail to impose control over them. The articles criticize the implications of this term in society, as it links these false attributes with a sense of manhood. The term also reinforces the false importance of maintaining a male-dominant relationship between the husband and his wife. This, in turn, could reflect the prevailing sense of a typical husband-wife relationship in the Gulf area in which the husband is expected to dominate and maintain power in the marriage relationship by not adhering entirely to his wife's demands or requests.

\section{"Dog" and "Donkey"}

As for the terms "dog" and "donkey," they can be approached from another perspective. Citizens of the Gulf countries are predominantly Muslims. Kuwait, for example, has only 289 Christian citizens and another 23 citizens whose religion was not stated, among its total 1,402,801 citizens, according to the official report of the Public Authority for Civil Information back in 2018. Accordingly, religion probably has a significant influence on 
people's practices, including their vocabulary choices; this can be conscious or unconscious (Moran, 2001). While it is not mentioned in the Quran, the holy book of Islam, some hadiths* present dogs as filthy and impure creatures. One hadith says that dogs' saliva is impure and that if any object comes in contact with saliva, the object must be purified: "When the dog licks the utensil, wash it seven times, and rub it with earth the eighth time" (Sahih Muslim, Hadith 551). Another hadith says that owning dogs for purposes other than farming and herding is not preferable in Islam: "Whoever keeps a dog, his good deeds will decrease every day by one 'qeeraat' [a unit of measurement] unless it is a dog for farming or herding" (Sahih Muslim, Hadith 2943). These hadiths, among others, represent dogs as despised creatures rather than likable, unlike in many other cultures such as the United States, for example, where dogs are considered human's best friends.

Therefore, citizens of the Gulf countries employ "dog" in their tweets in different phrases to insult others, such as "dog," "son of a dog," or even "daughter of a dog." While it is not mentioned in the samples collected in this study, one of the most used dog-related swearing phrases in the Gulf countries is "son/daughter of a sixteen dog," which assigns the addressee with the quality of dogs up to their sixteenth ancestor. Moreover, when one mentions dogs in their speech, it is usually collocated with the word "تكرم" or "حاثناك either before or after. They generally mean that the interlocutor acknowledges that the addressee is more valued and regarded to hear such a despicable word. The previous words are collocated with anything that is considered to be despicable or devalued, including some other animals (e.g., donkeys), and they often occur in more formal contexts.

The use of "donkey" might have a clear reason from a religious perspective also. The Quran explicitly loathes donkeys in many verses, as it represents them as unintelligent and ugly: "And walk thou at a moderate pace, and lower thy voice; verily, the most disagreeable of voices is the voice of the ass" (Quran 31:19). Also, "The likeness of those who were made to bear the law of Torah, but would not bear it, is as the likeness of an ass carrying a load of books" (Quran 62:5). Accordingly, calling people donkeys expresses that the speaker despises the addressee's characteristics, as it is meant to refer to their lack of intelligence. The only sample in the data where "donkey" is mentioned is "و الله انك مدرب حمار" (I swear, coach, you are a donkey), which supports the aforementioned hypothesis since it assigns the coach with lack of wisdom or intelligence, as he is believed to have contributed to the decision of stripping the player of the team captaincy; it is evident that the writer of this tweet stands with the player against the coach here. 


\section{"Bull" and "Cow"}

Languages, or more specifically cultures, share so many lexicons that have the same referents in the real world. Chinese and Arabic both have


in Arabic refer generally to a cow. However, they have totally different implications in both cultures. In Chinese, the term "cow" could be employed in the language to express admiration, as explained in one forum post discussion (Cragin, 2017) (e.g., You did a really good job today; you are a cow). Also, in Chinese, the cow is a lunar symbol, aligning itself with feminine qualities (Anjomshoa \& Sadighi, 2015). In Arabic, however, there is almost no possible context in which cows are employed to express admiration.

The two samples where "cow" was mentioned might indicate that it is aligned to feminist qualities in Arabic just like in Chinese: "ياخي البقره از عجتنا "أنقق خل تنفعه بقرنه" (I agree, let him be with his cow); they both refer to Icardi's agent/wife. Likewise, the bullwhich is a breed of cattle just like the cow, yet masculine - is also mentioned in the data: "الله يقلعك يا ثور" (get lost, you bull). However, it was assigned to a masculine referent instead, unlike cow. Based on the context, "cow" and "bull" seem to assign negative connotations to the referents in general, although it is impossible to know the writers' actual implications without investigating their intentions. While Haslam (2017) in his online article claimed that "cow" is used to refer to physical characteristics rather than psychological characteristics, the two tweets where "cow" was mentioned probably negate his claim since many might agree that the referent (the wife/agent) is not a stereotypical example of a person who is likely to be called a cow due to her physical appearance; she is relatively thin. However, the author did not take language or cultural variation into account, so it is assumed that he approached this from his own language or culture, which is AustralianEnglish. Accordingly, it can be claimed that in the third sample, "cow" referred to a negative psychological characteristic such as disagreeableness, just like "bull" in the other sample.

\section{Psychological Characteristics}

Swearing related to psychological characteristics came second, accounting for $21 \%$ of the overall data. These involved words or phrases that refer to abstract negative human qualities. Jay (1992) states that children often swear with reference to psychological characteristics. While it is difficult - if not impossible - to determine a Twitter user's age by merely examining their profile, it is unlikely that the collected tweets were written by children due to the sophisticated nature of the context in question in this study. In general, there are plenty of words and phrases that lie within the aforementioned notion of psychological characteristics, but they do not seem to have as strong or 
"غبي" offensive emotive connotations as in the other categories. For example, (idiot) and "فاسدة" (corrupt), as mentioned in the samples, do not seem as offensive as words or phrases in other categories such as "قحبة" (whore) as perceived in Arabian Gulf culture. Again, some might claim that terms such as "idiot" or "corrupt" would not be considered swear words, yet based on the criteria of swear words and phrases mentioned earlier in this paper, they do reflect a negative image on the target referents based on the cultural norms in the Arabian Gulf; therefore, they are considered swearing - at least for the sake of this paper.

After examining the data, the swear words and phrases collected in this category did not show significant restrictions for certain languages or cultures. That is, words such as "كذاب" (liar), "فقبرة" (loser), or (despicable) are more likely to be words that are commonly used in many other languages or cultures. It is difficult to claim that they are used more often in the Arabian Gulf region than in other regions without another comparative study of a different dialect.

\section{Whore-related}

Whore-related swearing constituted $16 \%$ of the overall data. What is worth observing here is the notion of "whore" in the Arab world. Which females are considered to be whores? According to an online article (Dream FM, 2016), the standards of labeling women as whores in the Arab world might be more complex than one thinks. To be more specific, not only are females who engage in sexual acts called whores, but also other females based on different ideologies in the Arab societies. For instance, many extremists consider a female who travels alone, smokes, wears short dresses or gets into friendship-relationships with males a whore. The reason this is mentioned is that there might be a potential reason why Icardi's agent/wife is associated with whore-related aspects: an old controversial incident in her personal life that every soccer fan knows about. Briefly, Nara's current husband, Icardi, was best friends with her previous husband, Maxi Lopez. The latter claims that while he had considered Icardi his best friend, Icardi stole his wife as she cheated on him while they were still married. This, in turn, might be perceived differently based on the conservative cultural norms of the Arabian Gulf countries. While she would not be considered a whore in many cultures around the world, it is not unlikely that she would be called a whore in the Arabian Gulf. The point is, it cannot be determined if she was associated with the quality of a whore due to her known past or if it was just a general reference to a pejorative term.

Moreover, the word "whore" was expressed in many forms in the data, in both colloquial and standard Arabic. Seven out of sixteen samples (44\%) were recorded in standard Arabic, "عاهرة", even when the rest of the tweet was 
written in colloquial Arabic in some cases. In one case, the standard Arabic form was modified as "عويرز," which is a form of the linguistic phenomenon "hypocorism."* This shift in style or formality might not be arbitrary; the writer might have opted for standard Arabic since swearing-and communication in general-usually occurs in colloquial Arabic, which is the natural, spontaneous form of speech. That is, colloquial swearing might leave more of a negative image on the interlocutor for violating cultural norms compared to the standard form, which is more formal in nature.

Although not mentioned in the samples, it is common in the Khaleeji dialect to employ "whore" to refer to the addressee's mother, as in "ابن القحبة (son of a whore). This might be in some ways similar to "son of a bitch" in English. In English-American English, for example - the word "bitch" is commonly used nowadays as a pejorative term for women in general. Although the word "bitch" has been used to refer to a female dog since about 1000 A.D., according to the Oxford English Dictionary, it also has other indications or references, including but not limited to "whore" (Gee, 2017).

\section{Religion-related}

Eight percent of the data was classified as containing religious references, such as "الله يلعنكم" (Allah damn you) and "الله يحرق و اندا" (Allah burn Wanda). Again, the Gulf countries are significantly impacted by Islam as the main religion in the region. While it cannot be claimed that all tweet writers of the data collected were actually Muslims - or practicing Muslims-, yet religion-related swear words is possibly coined in the lexicon as part of the widely heard words in the region. In other words, they became culturally based rather than religiously based. In addition, Ljung (2010) states that diabolic swearing involving the devil and hell do not seem to exist in Muslim cultures, but one of the collected samples contradicts this statement since hell was actually mentioned: "إلى الجحييي" (to heeeell). However, the tweet was written in colloquial Arabic first then shifted to standard Arabic. This shift from colloquial to standard in the same tweet can be a rich topic for further potential research. For the purpose of this paper, this will not be covered in order not to deviate from the main topic.

\section{Trash-related}

A total of $7 \%$ of the data was categorized as trash-related. While no references that discussed the topic in question were found for the sake of this paper, it can be claimed that calling someone "trash" cannot have positive indications in any imaginable context in any culture, for the word itself seems to have a universal negative connotation. In eight samples, referents were

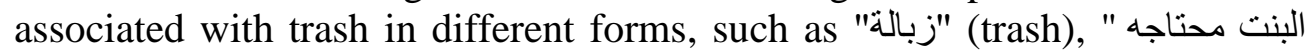

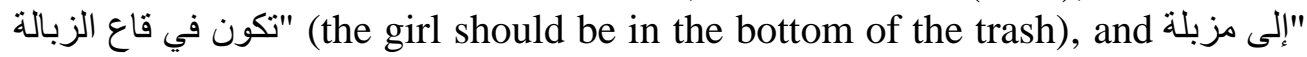


"التاريخ يا إيكاردي" (to the trash of history Icardi). This shows how creative swearers can be in manipulating words and associating several meanings with one phrase to insult others.

\section{Sex-related}

Sex-related vocabulary (5\%) provides a rich source for taboo terms and phrases that can be used to insult others. Languages around the world have their own sex organ-related terms that are commonly used by their speakers in different cultures or regions, depending on the context. For example, the male genitals are often referred to in different colloquial forms, such as "prick" in Britain and the United States. In Italian also, cazzo (prick) can be heard in heated discussions. Female organ-related terms are also used, such as "cunt" in English in general, not to mention sex-neutral terms such as "ass." All the aforementioned terms are used by both sexes, and they can refer to the same gender or opposite gender. In the data, explicit sex organ-related references appeared four times, three of which were explicit, as they were associated with motherhood as in "كس أمك" (your mother's cunt).

Just like sex organ-related terms, sexual activities in general also provide language users with many words or phrases that can be used in the act of swearing. In one of the tweets, sexual activity was implied rather than explicitly stated: "خل يمسكه" (let him hold it). On the literal surface, it is impossible to interpret the latter example without a given context, yet its implication is understood in the context in which the tweet was written. The latter sample shows that implications vary in degree and that context plays a fundamental role in interpreting or understanding swear words.

\section{Physical Characteristics}

Swearing in this category constituted $4 \%$ of the data. Just like psychological characteristic-based swearing, according to Jay (1992), children's insults are also based on physical characteristics. This might also indicate that they are not as strong or offensive as other swearing used by adults. Hence, whenever they are used by adults, they are intended to be less offensive. As recorded in the four samples in this category: "شمطاء" (hoary), "صليعان" ("أم ضروس" (baldy), (toothy), and "بو ديود (booby), they do sound more descriptive and humorous rather than offensive. Hence, they might be good examples of swearing triggered by humor rather than anger (Stone \& McMillan, 2012). However, this cannot be verified without direct examination of the writer's psychological condition when a tweet was written. 


\section{Shit-related}

Jay (1992) provides a comprehensive analysis of shit-related swearing in American culture and how children use these swear words compared to adults:

Scatological terms refer to human waste products and processes. Such terms are among the early words that children hear and use when they are toilet trained. American have a great penchant for coining childish terms rather than using standardized terms or those of scientific origin. Scatological insults are common among children. Different cultures pay attention to different types of taboo. American have a penchant for sexual and religious terms; French insults are more sexual than Americans and the Germans appear to be more attentive to scatological reference than others. The terms children say are usually different than those that adults would pick for the same referent. Some only say the vulgar would use scatological terms, when a more refined euphemism or technical term could be substituted.

Since scatological references are about feces and elimination they appear as:

Poo Poo, ka ka, poop, turd, crap, shit, ass Shit for brains, piss, piss pot, piss off, fart. (p. 9)

While only $2 \%$ of the data was scatological, the words were colloquial rather than formal; "زق" (shit), not "براز" (feces), as explained by Jay (1992). Accordingly, although it was not one of the most chosen categories as seen in the data, scatological insults are among those that Khaleejis opt for when swearing on Twitter.

\section{Hay- and Sand-related}

Nearly $3 \%$ of the data contained abnormal activities that are uncommon among human beings, e.g., portraying them eating hay or sand. Obviously, a logical situation where a human being eats sand cannot be imagined, and if this does occur, it must be offensive or maybe humorous depending on the context. Hence, abnormal activities are also sources of insults as recorded in the data: "أكل تراب" (eat sand). On the other hand, أكل" تبن(eat hay) can also be associated with animal-related swearing since hay is animal fodder usually eaten by horses, goats, sheep, etc. Accordingly, these words are meant to humiliate the target person by associating them with animal behaviors or activities.

\section{Loss of Face}

This was not intended to be part of this study, but the data paved the way for another interesting topic, which is individuals' loss of face when swearing. Based on the aforementioned data analysis, it is possible to say that 
swearing can harm swearers' status and how they are perceived by others in the context in which the swearing occurs. According to Stapleton (2010) and Johnson and Lewis (2010), swearing is a violation of norms, and this may lead to the swearer's loss of face due to negative judgments by others. Approximately one week after collecting the data, the samples were reexamined to analyze them from a different point of view, yet six out of the one hundred samples had been deleted; only ninety-four samples remained. The goal was to examine which swearing categories might potentially cause loss of face the least/most.

On Twitter, people may choose to reveal their real identities in their accounts or simply fake them for their own reasons. Some might have their real names as well as their personal pictures, while others might choose one of these or neither. On the other hand, many accounts do not reveal the owner's identity; the owner chooses to use nicknames and non-personal profile pictures. Thus, it was assumed that those who had their personal pictures in public were less likely to risk loss of face by writing the most obscene swear words, especially in conservative societies such as in the Gulf countries. Accordingly, all accounts were re-examined to record how many had personal pictures of their owners. Then the recorded swear words were classified again based on the same categorization implemented earlier in this paper. The initial hypothesis was that accounts with real profile pictures would avoid using the most obscene swearing to avoid loss of face on Twitter or at least minimize it.

Figure 3: Ratio of accounts with personal pictures

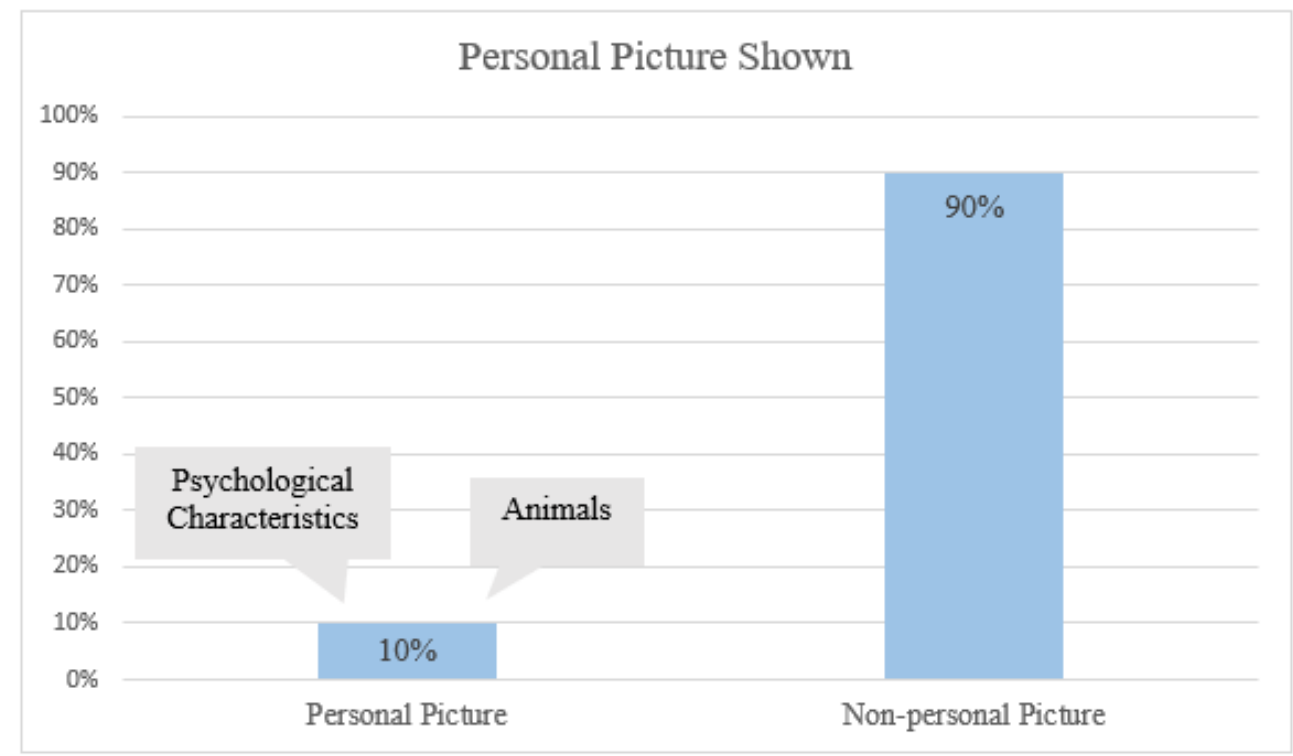

After examining the accounts, it was found that only $10 \%$ showed their owners' real pictures. The analysis showed that swearing recorded in the 
tweets from those with real pictures was related to two categories only: psychological characteristics and animals. As mentioned earlier, it is assumed that the more obscene the swearing is, the more likely the swearer will lose face due to negative judgment by others on a public platform like Twitter. Accordingly, it can be stated that the aforementioned categories are not the most offensive swearing — or among the least offensive - in the Gulf culture since swearers opted for them although their personal pictures were shown in public, not afraid to be judged negatively and lose face.

\section{Conclusion}

The findings provide us with informative explanations and justifications about swearing choices in the Khaleeji dialect, each of which reflects on the culture, religion, and language from different points of view.

Khaleejis rely heavily on language about animals to unleash their anger or disapproval as they insult others through swearing. Their choices of animals have different justifications, some of which are significantly different from those of other languages or cultures. For instance, the reference to sheep reflects the patriarchal values that dominate the Khaleeji culture in which men are expected to be dominants over women in relationships. Also, the reference to cows in swearing manifests how animals have different connotations in cultures around the world; certain animals like cows have a positive connotation in Chinese, whereas in Arabic -including the Khaleeji culture or dialect- they have a negative connotation. It is clear also that religion has an impact on swearing vocabulary in the Khaleeji dialect, which is represented by the choice of swear words and phrases recorded. Dogs and donkeys, for example, are portrayed mostly negatively in Islam. This, in turn, shaped people's overall attitudes toward them, which transferred to their choice of words and logic in certain discourses where swearing occurs. The influence of religion is also seen more clearly through Khaleejis' explicit use of religiousrelated words and phrases such as "Allah damn you." In addition, referring to females as whores in the Khaleeji culture has more complex dimensions compared to other cultures since there is no fine line by which females can be labeled as whores based on the culture's norms. That is, the image of a whore in the Khaleeji culture is not restricted to sexual acts only but also to several other personal attributes that are perceived negatively by different segments of the society. Sexual references as well as psychological and physical characteristics are also within Khaleejis lexicon in swearing along with shitrelated and trash-related words, not to mention the reference to hay and sand in different forms. Furthermore, the last section shows that opting for animals and psychological characteristics to swear does not seem as aggressive or offensive in the Khaleeji dialect as other swearing categories. Psychological characteristics as well as animal-related swear words were employed in tweets 
by writers that had their personal picture shown in public, which indicates that swearing in these categories is not perceived as too obscene in a way that would cause an extreme loss of face.

However, the study has a number of limitations. First, in order to better understand and generalize the data, it is better to have a comparative dialect through which we can see the similarities and differences of swearing categorization in each dialect. This would help identify whether there are words or categories that are used considerably more in some dialects compared to others. For example, the data can be compared to another Arabic dialect so we can capture the uniqueness of the Khaleeji dialect in specific compared to other Arabic dialects. Second, the context in which the data were collected may have influenced people's choice of words and phrases. For instance, the soccer-related topic in this study involved referents from both genders (the player and his agent/wife), and the latter has a controversial past herself. If the agent/wife was not part of the context, whore-related swearing might not have been as high as recorded in the study. The same applies to the reference to sheep in the samples; they were probably high due to the specific context of the topic. Nevertheless, every topic has its own unique details that would definitely influence a person's choice of words in one way or another. It is hoped that the findings of this study are insightful for further research on swearing-related topics, whether in the Khaleeji dialect or any other dialect since the data can be analyzed from multiple viewpoints.

\section{Notes}

Hadiths are the records of the words, actions, and silent approval traditionally attributed to the Islamic prophet Muhammad. The authority of hadith as a source for religious law and moral guidance ranks second only to that of the Quran (which Muslims hold to be the word of Allah revealed to his messenger Muhammad).

A hypocorism is a diminutive form of a word or a given name created by shortening or phonetically altering it (e.g., Michael = Mikey).

\section{References:}

1. Alhaidari, M. (2014, February 28). Nothing ruined us more than "be a wolf with your wife, not a sheep!" Alriyadh Newspaper. http://www.alriyadh.com/914134

2. Allan, K., \& Burridge, K. (1991). Euphemism \& dysphemism: Language used as shield and weapon. Oxford University Press.

3. Alodhaidan, S. (2015, April 28). The sheep husband. Aleqtisadiya Newspaper. http://www.aleqt.com/2015/04/28/article_953164.html

4. Anjomshoa, L., \& Sadighi, F. (2015). The comparison of connotative meaning in animal words between English and Persian expressions and 
their translation. International Journal on Studies in English Language and Literature, 3(2), 65-77.

5. Cragin, D. (2017). You're a cow. Language Log. http://languagelog.ldc.upenn.edu/nll/?p=31846

6. Dream FM. (2016, June 2014). The whore, the view of Arab Society of

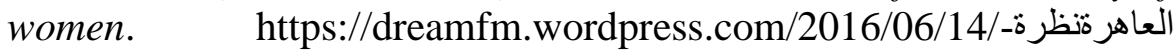



7. Finn, E. (2017). Swearing: The good, the bad \& the ugly. ORTESOL Journal, 34(1), 17-26. https://doi.org/10.5089/9781484315163.001

8. Gee, S. (2017). Is "son of a bitch" meant to offend the "son" or the "mother"? Quora. https://www.quora.com/Is-son-of-a-bitch-meant-tooffend-the-son-or-the-mother

9. Haslam, N. (2017, April 18). Why it's so offensive when we call people animals. The Conversation. https://theconversation.com/why-its-sooffensive-when-we-call-people-animals-76295

10. Jay, T. (1992). Cursing in America: A psycholinguistic study of dirty language in the courts, in the movies, in the schoolyards, and on the streets. John Benjamins Publishing.

11. Jay, T., \& Janschewitz, K. (2008). The pragmatics of swearing. Journal of Politeness Research. Language, Behaviour, Culture, 4(2), 267-288. https://doi.org/10.1515/JPLR.2008.013

12. Johnson, D. I., \& Lewis, N. (2010). Perceptions of swearing in the work setting: An expectancy violations theory perspective. Communication Reports, 23(2), 106-118. https://doi.org/10.1080/08934215.2010.511401

13. Ljung, M. (2010). Swearing: A cross-cultural linguistic study. Springer.

14. Mercury, R. E. (1995). Swearing: A" bad" part of language; A good part of language learning. TESL Canada journal, 13(1), 28-36. https://doi.org/10.18806/tesl.v13i1.659

15. Moran, R. (2001). Teaching culture: Perspectives in practice. Heinle.

16. Mubarak, H., Darwish, K., \& Magdy, W. (2017). Abusive language detection on Arabic social media. In Z. Waseem, W. H. Kyong Chung, D. Hovy, \& J. Tetreault (Eds.) Proceedings of the First Workshop on Abusive Language Online (pp. 52-56). Vancouver, Canada: Association for Computational Linguistics.

17. Muslim ibn al-Hajjaj. (2003). Sahih Muslim. In J. L. Esposito (Ed.), The Oxford dictionary of Islam. Oxford University Press.

18. Pamungkas, E. W., Basile, V., \& Patti, V. (2020). Do you really want to hurt me? Predicting abusive swearing in social media. In Proceedings of the 12th Conference on Language Resources and 
Evaluation (pp. 6237-6246). European Language Resources Association.

19. Radcliffe, D., \& Lam, A. (2018). Social media in the Middle East: The story of 2017. University of Oregon. http://dx.doi.org/10.2139/ssrn.3124077

20. Stapleton, K. (2010). Swearing. In M. Locher \& S. Graham (Eds.), Interpersonal pragmatics (pp. 289-305). Walker de Gruyter $\mathrm{GmbH} \& \mathrm{Co}$.

21. Stone, T., \& McMillan, M. (2012). Warning-this job contains strong language and adult themes: Do nurses require thick skins and broad shoulders to deal with encounters involving swearing? In D. Holmes, T. Rudge, \& A. Perron (Eds.), (Re)thinking violence in health care settings: A critical approach (pp. 259-279). Routledge.

22. Taylor, B. A. (1995). Offensive language: A linguistic and sociolinguistic perspective. In D. Eades (Ed.), Language in evidence: Issues confronting aboriginal and multicultural Australia (pp. 219258). UNSW Press.

23. Vingerhoets, A. J., Bylsma, L. M., \& De Vlam, C. (2013). Swearing: A biopsychosocial perspective. Psihologijske teme, 22(2), 287-304. 